\title{
A stereoselective, catalytic strategy for the in-flow synthesis of advanced precursors of rasagiline and tamsulosin
}

\author{
Davide Brenna ${ }^{a}$, Margherita Pirola ${ }^{a}$, Laura Raimondi ${ }^{a}$, Anthony J. Burke ${ }^{\mathrm{b}}$, Maurizio Benaglia ${ }^{\mathrm{a}, *}$ \\ a Dipartimento di Chimica, Universita' degli Studi di Milano, via Golgi 19, 20133 Milano, Italy \\ ${ }^{\mathrm{b}}$ Department of Chemistry and Chemistry Center of Évora, University of Évora, Rua Romão Ramalho, 59, 7000 Évora, Portugal
}

\section{A R T I C L E I N F O}

\section{Article history:}

Received 24 December 2016

Revised 12 January 2017

Accepted 14 January 2017

Available online 21 January 2017

\section{Keywords:}

Active pharmaceutical ingredients

Flow reactors

Stereoselective synthesis

Reduction

Flow chemistry

Chiral amines

Metal-free catalysis

\begin{abstract}
A B S T R A C T
The diastereoselective, trichlorosilane-mediate reduction of imines, bearing different and removable chiral auxiliaries, in combination either with achiral bases or catalytic amounts of chiral Lewis bases, was investigated to afford immediate precursors of chiral APIs (Active Pharmaceutical Ingredients). The carbon-nitrogen double bond reduction was successfully performed in batch and in flow mode, in high yields and almost complete stereocontrol. By this metal-free approach, the formal synthesis of rasagiline and tamsulosin was successfully accomplished in micro(meso) flow reactors, under continuous flow conditions. The results of these explorative studies represent a new, important step towards the development of automated processes for the preparation of enantiopure biologically active compounds.
\end{abstract}

(C) 2017 Elsevier Ltd. All rights reserved.

\section{Introduction}

Rasagiline mesylate (Scheme 1), also known as $(R)-(+)-N-$ propargyl-1-aminoindan mesylate, is a commercially marketed pharmaceutically active substance, under the brand name azilect ${ }^{\circledR}$. The racemic form of the drug was patented by Aspro Nicholas in the early 1979 , and was later found to be indicated for treatment of Parkinson's disease (PD), being effective both as monotherapy in early PD, and as adjunctive in patients with advancing PD and motor fluctuations. ${ }^{1}$ This chiral amine is a potent second-generation propargylamine pharmacophore that selectively and irreversibly inhibits the $\mathrm{B}$-form of the monoamineoxidase enzyme (MAO-B) over type A by a factor of fourteen. ${ }^{2}$ European drugregulatory authorities approved this potent MAO-B inhibitor in February 2005 and the US FDA in May 2006. ${ }^{3}$ Although the $\mathrm{S}$-(-)-enantiomer of $\mathrm{N}$-propargyl-1-aminoindane still exerts some neuroprotective properties, the potency of $\mathrm{R}$-(+)-enantiomer against the MAO-B enzyme is approximately 1000-fold higher. Different strategies aimed to the preparation of the enantiopure compound have been explored, ${ }^{4}$ but, at the best of our knowledge, a stereoselective organocatalytic approach for the preparation of

\footnotetext{
* Corresponding author.

E-mail address: maurizio.benaglia@unimi.it (M. Benaglia).
}

rasagiline has never been reported so far. We report here a metal-free stereoselective strategy for the synthesis of rasagiline and of an advanced intermediate of another API, tamsulosin, sold under the trade name flomax as single enantiomer. Active as antagonist for $\alpha_{1 \text { a }}$ adrenergic receptor, It is used to treat symptomatic benign prostatic hyperplasia and to treat urinary retention. Starting from this common precursor, different pharmaceutically active compounds could be prepared, having as biological targets different receptors such as cholinesterase and monoamine oxidase inhibition, ${ }^{5} \sigma$-receptors ${ }^{6}$ and human adenosine $A_{2 A}$ receptor. ${ }^{7}$

The synthetic plan for the preparation of the two-target molecules involves a metal-free stereoselective reduction of imines, easily prepared starting from commercially available ketones (Scheme 1). ${ }^{8}$

\section{Results and discussions}

We initially explored the possibility to use a catalytic amount of chiral Lewis base (LB) for the stereoselective, trichlorosilane-mediated reduction of the imine prepared starting from 1-indanone. Two different chiral picolinamides, previously developed in our group, were tested. ${ }^{9,10}$ Using ephedrine-derived catalyst $\mathbf{A}$, the chiral amines were obtained in high yields, both using PMP (paramethoxyphenyl) and benzyl protected imines, but with modest 


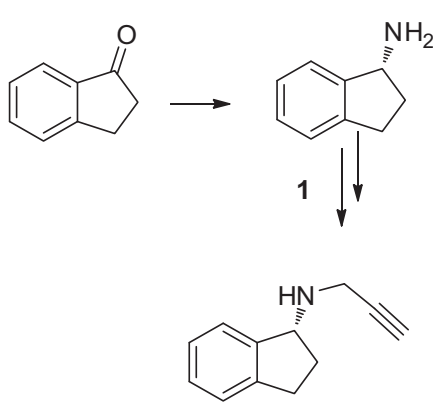

Rasagiline<smiles>COc1ccc(CC(C)=O)cc1</smiles><smiles>CCOc1ccccc1OCCN[C@H](C)Cc1ccc(OC)cc1</smiles>

Tamsulosin

Scheme 1. Synthetic strategy for the synthesis of rasagiline and tamsulosin.

enantioselectivities, up to $60 \%$. e.e. for the $(R)$-enantiomer. No better results were observed with catalyst type $\mathbf{B}$, that is known to lead to the formation preferentially of the $(S)$-isomer (see Scheme 2). ${ }^{10}$

Then, we decided to explore the use of a chiral auxiliary, by employing $\alpha$-methylbenzylamine as cheap and readily removable element of stereocontrol in the reduction, that was already successfully employed in previous works (Scheme 3). ${ }^{8 \mathrm{j}}$ As achiral Lewis base, $N, N$-dimethyl formamide was selected as well established, inexpensive and efficient activator of trichlorosilane for the reduction of ketoimines. ${ }^{8 \mathrm{j}, 9}$

Reductions were performed starting from a diastereoisomeric mixture of imine 3, prepared from $1-(R)$-phenylethylamine in a 9:1 (3c:3d) ratio, in favor of the $E$ imine $3 c$. The best results were achieved working at $-20^{\circ} \mathrm{C}$, and performing the reaction for $36 \mathrm{~h}$; the product was obtained in 55\% yield and 98:2 diastereomeric ratio in favor of the $(R, R)$ stereoisomer $\mathbf{4 c}$ (Table 1 , entry $5)$. To achieve complete conversion higher reaction temperature were needed (Table 1 , entry 6 ), leading to a small decrease of diastereoselection (90:10 of d.r.).

Finally, in the attempt to increase further the efficiency of the process, the use of a match combination between the chiral auxiliary and the chiral catalyst was investigated. Based on previous works, ${ }^{9}$ we selected the known favorable combination of catalyst A and 1-(R)-phenylethylamine as chiral auxiliary: the reduction was accomplished in 90\% conversion and a 90:10 of d.r. ratio (Table 1, entry 7). Since the use of catalyst $\mathbf{B}$, that leads to formation of products of $(S)$ configuration, ${ }^{10}$ afforded, as expected, the product in lower stereoselectivity (entry 8 , mismatch couple with the chiral auxiliary that favours the formation of product with $(R)$ configuration), the use of pseudo-enantiomer of catalyst $\mathbf{B}$ allowed to obtain the product $\mathbf{4 c}$ in $80 \%$ conversion and a complete diasteroselectivity (Table 2, entry 9 ).

With the best reaction conditions in our hands, we decided to explore the possibility of employing different chiral auxiliaries. Since the removal of the $\alpha$-methylbenzylamine tipycally requires palladium catalysts, ${ }^{11}$ we focused our attention onto the use of a chiral auxiliary removable without the need of precious transition metals. In particular, we selected commercially available (R)-4-methoxy- $\alpha$-methylbenzylamine and (R)-2-methyl-2propanesulfinamide since they could be removed under metal-free conditions. ${ }^{12,13}$

Imines $\mathbf{5 a}$ and $\mathbf{6 a}$ were readily synthesized and their reduction was performed in the presence of $3.5 \mathrm{~mol}$ eq. of trichlorosilane and stoichiometric amounts of DMF or catalytic amounts of chiral picolinamide A (see Scheme 4).

Imine 5a was efficiently reduced using DMF as achiral LB (Table 2 , entry 1 ), with high conversion (80\%) and a complete diasteroselectivity. In order to increase the yield, the reaction was then performed in the presence of catalyst $\mathbf{A}$ (Table 2, entry 2); complete conversion of the starting material into the chiral amine $\mathbf{5 b}$ and a total stereocontrol of the reaction were observed.

Analogously, the reduction of imine $\mathbf{6 a}$ was efficiently promoted by catalyst $\mathbf{A}$, affording the product $\mathbf{6 b}$, that was in situ deprotected during the basic aqueous work up, to afford the primary chiral amine 1 in quantitative yield and $60 \%$ e.e. (entry 4 , Table 2).

Considering the raising interesting for the flow preparation of API's, ${ }^{14}$ based on these results and with the aim to further accelerate the reaction, we explored the possibility of developing<smiles>C[C@H]([C@H](O)c1ccccc1)N(C)C(=O)c1cc(Cl)ccn1</smiles><smiles>C=C[C@H]1CN2C[C@H]1[C@H](C(NC(=O)c1ccccn1)c1ccnc3ccccc13)N2</smiles>

B<smiles>O=PN=C1CCc2ccccc21</smiles>

PG: PMP 3a

$P G: B n \quad 3 b$

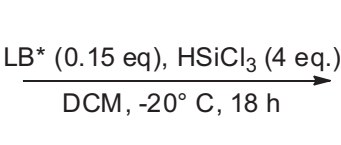

PG: PMP 4a

$P G: B n \quad 4 b$
CAT A

$92 \%$ Y; $35 \%$ e.e. $85 \%$ Y; $60 \%$ e.e.
CAT B

$0 \%$ Y; e.e.n.d

$80 \%$ Y; $55 \%$ e.e.

Scheme 2. Enantioselective reductions of imines for the synthesis of rasagiline intermediates. 


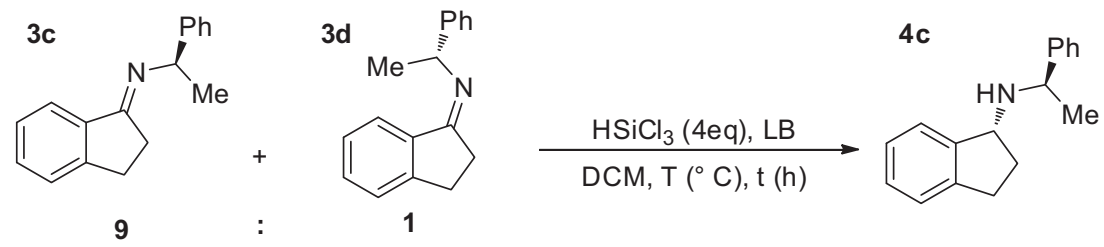

Scheme 3. Stereoselective reductions of chiral imines 3c/3d.

Table 1

Reductions of chiral imine 3c/3d.

\begin{tabular}{|c|c|c|c|c|c|}
\hline Entry & LB & $\mathrm{T}\left({ }^{\circ} \mathrm{C}\right)$ & $\mathrm{t}(\mathrm{h})$ & Conv. (\%) & d.r. ${ }^{b}$ \\
\hline 1 & DMF & 0 & 18 & 67 & $90: 10$ \\
\hline 2 & $\mathrm{DMF}$ & -10 & 18 & 44 & $90: 10$ \\
\hline 3 & DMF & -10 & 36 & 42 & $90: 10$ \\
\hline $4^{c}$ & DMF & 0 & 36 & 77 & $90: 10$ \\
\hline $5^{c}$ & DMF & -20 & 36 & 55 & $98: 2$ \\
\hline 6 & DMF & 0 to $\mathrm{rt}$ & 18 & 98 & $90: 10$ \\
\hline $7^{d}$ & A & -20 & 36 & 90 & $90: 10$ \\
\hline $8^{d}$ & B & -20 & 36 & 20 & $76: 24$ \\
\hline $9^{\mathrm{d}, \mathrm{e}}$ & B & -20 & 36 & 80 & $>98: 2$ \\
\hline
\end{tabular}

a Conversions were evaluated on ${ }^{1} \mathrm{H}$ NMR

b d.r. were evaluated on crude mixtures using ${ }^{1} \mathrm{H}$ NMR.

c $\mathrm{HSiCl}_{3}$ was further added every $12 \mathrm{~h}$.

d Reaction was performed using 0.15 eq. of chiral LB.

e Reaction was promoted by the pseudoenantiomer of catalyst $\mathbf{B}$.

Table 2

Reduction of chiral imines 5a-6.

\begin{tabular}{lllll}
\hline Entry & Imine & LB & Conv. (\%) & d.r. \\
\hline $1^{\text {a }}$ & $\mathbf{5 a}$ & DMF & 80 & $>98: 2$ \\
$2^{\text {b }}$ & $\mathbf{5 a}$ & $\mathbf{A}$ & 98 & $>98: 2$ \\
$3^{\mathrm{a}}$ & $\mathbf{6 a}$ & DMF & $<5$ & ND \\
$4^{\mathrm{c}}$ & $\mathbf{6 a}$ & $\mathbf{A}$ & 99 & $80: 20$
\end{tabular}

a 5 eq. of DMF were used.

b 0.15 eq of catalys were used.

c The product was obtained as primary amine directly after the work up; e.e. was determined by HPLC on chiral column (see the Supporting Information).<smiles>COc1ccc(C(C)N=C2CCc3ccccc32)cc1</smiles>

$5 \mathbf{a}$<smiles>CC(C)(C)S(=O)N=C1CCc2ccccc21</smiles>

$6 a$

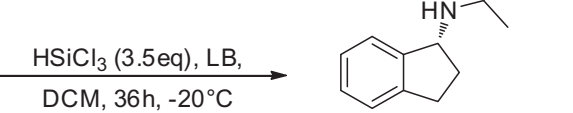

$5 b$

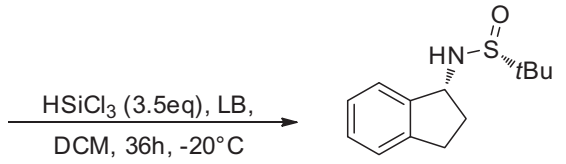

$6 b$
Scheme 4. Stereoselective reductions of chiral imines $\mathbf{5 a - 6 a . ~}$

a continuous flow methodology for the preparation of rasagiline. Recently our group has demonstrated that $\mathrm{HSiCl}_{3}$-mediated diastereoselective imine reduction could be efficiently performed in (micro)-mesoreactors under continuous flow conditions. ${ }^{15}$
The experimental set up involves a coil-reactor, realized by using PTFE tubing ( $1.58 \mathrm{~mm}$ outer diameter, $0.58 \mathrm{~mm}$ inner diameter, $1.89 \mathrm{~m}$ length, $500 \mu \mathrm{L}$ effective volume) coiled in a bundle and immersed in a bath cooled to the desired temperature. A syringe pump, equipped with two Hamilton gastight syringes, fed the solution containing the imine and the Lewis base dissolved in DCM, and the solution of trichlorosilane in DCM through a $T$-junction into the coil-reactor (Scheme 5).

Running the reduction of imine $5 \mathbf{a}$ at low temperature $\left(17^{\circ} \mathrm{C}\right)$, low conversions were detected; when the reaction was performed at $30{ }^{\circ} \mathrm{C}$, the product was isolated in $83 \%$ yield but, as expected, with a lower disatereoisomeric ratio (92:8, entry 4 , Table 3$)$. In order to achieve a complete stereocontrol, the reaction was run in the flow reactor in the presence of catalyst $\mathbf{A}$; operating at $30{ }^{\circ} \mathrm{C}$ and with a 30 min residence time, the matching combination of an enantiopure catalyst with the chiral auxiliary, the chiral amine 5b was in continuo produced in $70 \%$ yield as stereoisomerically pure compound (entry 5 , Table 3 ).

The synthesis of an advanced intermediate of tamsulosin was then studied. By following the same synthetic approach and taking advantage of the previously used chiral auxiliaries, enantiopure imines 7a and $\mathbf{8 a}$ were synthesized and their reduction studied in batch (Scheme 6).

The results are reported in Table 4; when using an achiral base (DMF), the reduction of imine 7a proceeds with a modest diastereoselectivity, and only with catalyst $\mathbf{B}$ an improved stereocontrol was obtained, although the product was isolated in 50\% yield only. However, starting from chiral imine 8a better results were achieved; simply using a combination of two very cheap reagents, like trichlorosilane and $\mathrm{N}, \mathrm{N}$-dimethylformamide, the primary amine $\mathbf{2}$ was directly obtained after the work up in quantitative yield and $94 \%$ e.e. (entry 9 , Table 4 ).

The reaction was then performed in the previously described flow reactor system (Scheme 7); with imine 7a the in-flow reduction nicely reproduced the results of the in batch procedure (entries 1-2, Table 5); interestingly, it was possible to achieve the removal of the chiral auxiliary under continuous flow 


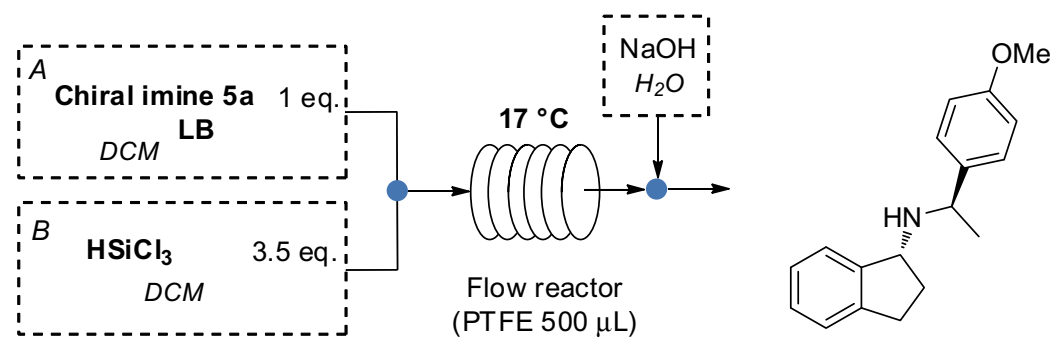

Scheme 5. Continuous flow preparation of an advanced precursor of rasagiline.

Table 3

In-flow synthesis of an advanced intermediate of rasagiline.

\begin{tabular}{|c|c|c|c|c|c|c|c|}
\hline Entry & LB & Imine & $\mathrm{T}\left({ }^{\circ} \mathrm{C}\right)$ & Residence time (min) & Eq. & Conv. (\%) & d.r. \\
\hline 1 & DMF & $5 \mathbf{a}$ & 17 & 10 & 5 & 20 & $98: 2$ \\
\hline 2 & DMF & $5 \mathbf{a}$ & 17 & 20 & 5 & 34 & $98: 2$ \\
\hline 3 & DMF & $5 \mathbf{a}$ & 17 & 30 & 5 & 35 & $98: 2$ \\
\hline 4 & DMF & $5 a$ & 30 & 20 & 5 & 83 & $92: 8$ \\
\hline 5 & A & $5 \mathbf{a}$ & 30 & 20 & 0.2 & 70 & $>98: 2$ \\
\hline
\end{tabular}<smiles>COc1ccc(C/C(C)=N/C(C)c2ccccc2)cc1</smiles>

$7 a$<smiles>CC[C@@H](C)S(=O)/N=C(\C)Cc1ccc(OC)cc1</smiles>

$8 a$

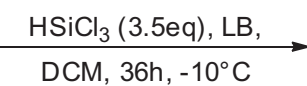

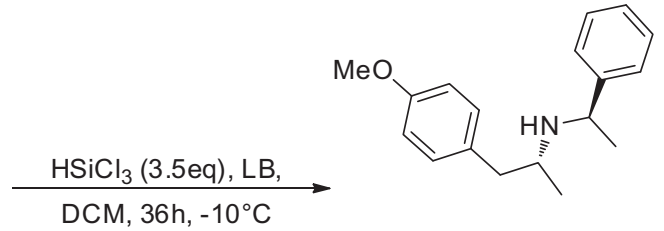

$5 b$<smiles>COc1ccc(C[C@H](C)NS(=O)CC(C)(C)C)cc1</smiles>

$8 \mathbf{b}$

Scheme 6. In batch synthesis of advanced precursors of tamsulosin.

Table 4

In batch synthesis of tamsulosin precursor.

\begin{tabular}{|c|c|c|c|c|c|}
\hline Entry & LB & Imine & Eq. & Conv. (\%) & d.r. \\
\hline $1^{\mathrm{a}}$ & DMF & $7 a$ & 5 & 99 & $65: 35$ \\
\hline $2^{\mathrm{b}}$ & DMF & $7 a$ & 5 & 99 & $70: 30$ \\
\hline 3 & DMF & $7 a$ & 5 & 99 & $77: 23$ \\
\hline 4 & A & $7 a$ & 0.15 & $<5$ & n.d. \\
\hline 6 & B & $7 a$ & 0.15 & 50 & $92: 8$ \\
\hline 7 & A & $8 a$ & 0.15 & $<5$ & n.d. \\
\hline 8 & B & $8 a$ & 0.15 & 45 & n.d. \\
\hline $9^{c}$ & DMF & $8 a$ & 0.15 & 99 & $93: 7^{c}$ \\
\hline
\end{tabular}

a Reaction performed from $0{ }^{\circ} \mathrm{C}$ to room temperature.

b Reaction performed at $0{ }^{\circ} \mathrm{C}$.

c The product was obtained as primary amine directly after the work up; e.e. was determined by HPLC on chiral column (see the Supporting Information).

conditions, as shown in eq.A of Scheme 5. The continuous hydrogenolysis of chiral amines was performed with a ThalesNano $\mathrm{H}$-Cube $\mathrm{Mini}^{\mathrm{TM}}$, equipped with a $10 \% \mathrm{Pd} / \mathrm{C}$ cartridge; at $50{ }^{\circ} \mathrm{C}$ and 50 bar, after $1 \mathrm{~h}$, chiral amine 2 was obtained in quantitative yield.
When enantiopure imine 8a was reduced with DMF and trichlorosilane in the PTFE flow reactor, the chiral primary amine 2 was directly produced and was collected out from the flow reactor, after in line basic aqueous work up, in 70\% isolated yield and $88 \%$ e.e. (entries $3-4$, Table 5 ). 
Eq. A

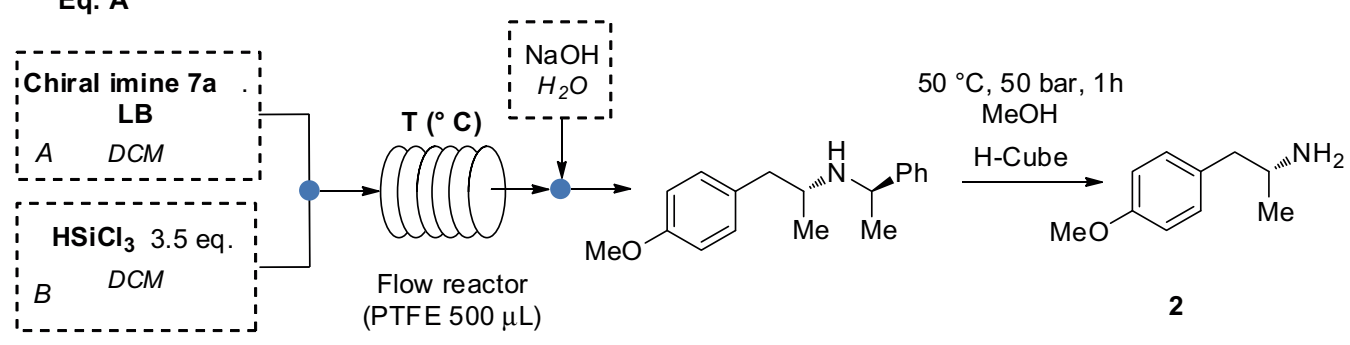

Eq. B

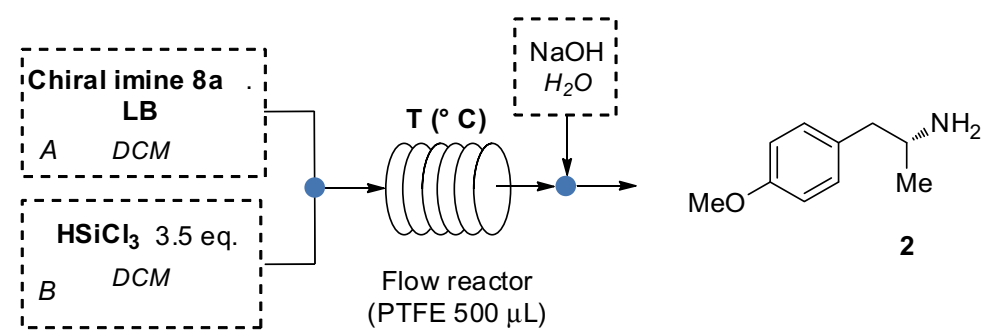

Scheme 7. In-flow synthesis of chiral amine $\mathbf{2}$, a tamsulosin precursor.

Table 5

Continuous flow reduction of chiral imines $7 \mathbf{a}$ and $\mathbf{8 a}$

\begin{tabular}{|c|c|c|c|c|c|c|}
\hline Entry & LB & Imine & Residence time (min) & Eq. & Conv. (\%) & d.r. \\
\hline 1 & B & $7 a$ & 20 & 0.2 & 60 & $92: 8$ \\
\hline 2 & B & $7 a$ & 30 & 0.2 & 75 & $92: 8$ \\
\hline $3^{a}$ & $\mathrm{DMF}$ & $8 a$ & 20 & 5 & 60 & $94: 6^{a}$ \\
\hline $4^{\mathrm{a}}$ & DMF & $8 a$ & 30 & 5 & 70 & $94: 6^{\mathrm{a}}$ \\
\hline
\end{tabular}

a The product was obtained as primary amine directly after the work up; e.e. was determined by NMR with chiral shift-agents (see the Supporting Information).

\section{Conclusions}

In the present study, a stereoselective, metal-free strategy for the synthesis of chiral amines, direct precursors of rasagiline and tamsulosin, was developed. After setting up the reaction conditions in batch, the stereoselective trichlorosilane-mediated reduction of chiral imines was efficiently performed under continuous flow conditions. Chiral primary amines were obtained either by a continuous flow hydrogenolysis, or directly out from the flow reactor after an in-line aqueous work up, depending on the chiral auxiliary group at the amine nitrogen atom.

The present work represents a further step towards the development of a multistep continuous flow process for the synthesis of enantiomerically pure pharmaceutically relevant amines.

\section{Acknowledgements}

DB thanks Università degli Studi di Milano for a Ph.D. fellowship; MB thanks CNR for the bilateral project FCT/CNR 20152016 (Ref. 441.00) "Exploring novel organocatalytic enantioselective reductions for accessing key drugs for Neurodegenerative disease treatment". AJB thanks bilateral project FCT/CNR 2015-2016 (Ref. 441.00).

\section{A. Supplementary material}

Supplementary data associated with this article can be found, in the online version, at http://dx.doi.org/10.1016/j.bmc.2017.01.023.

\section{References}

1. (a) Sudhir MS, Nadh RV. Drug Invent Today. 2013;5:133-138;

(b) Fernández M, Negro S, Slowing K, Fernández-Carballido A, Barcia E. Int J Pharm. 2011;271-280;

(c) Weinreb O, Amit T, Riederer P, Youdim MBH, Mandel SA. International Review of Neurobiology. New York: Academic Press; 2011. 281.

2. Fernández M, Barcia E, Fernández-Carballido A, Garcia L, Slowing K, Negro S. Int J Pharm. 2012;266-278.

3. Guay DRP. Am I Geriatr Pharmacother. 2006:330-346.

4. (a) For selected examples of kinetic resolution see: Selic L. WO Patent 064216 2011, to LEK Pharmaceuticals.;

(b) Thanedar AA, Deshmukh SA, Zope SS, Kelkar LM, Koilpillai JP, Gajera JM. WO Patent 048 612, 2011, to Glenmark Generics Limited.;

(c) For selected examples of enzymatic preparation see: Malik MS, Park E-S Shin J-S. Green Chem. 2012;14:2137-2140;

(d) Ma G, Xu Z, Zhang P, et al. Org Process Res Dev, 2014, 5, 1169-1174.

(e) . For catalytic and stereoselective metal based methodologies see:Brunner R, Becker R, Gauder S. Organometallics. 1986;5:739-746;

(f) Takei I, Nishibayashi Y, Ishii Y, Mizobe Y, Uemura S, Hidai M. Chem Commun, 2001, 44, 2360-2361.;

(g). For selected examples of the use of chiral auxiliary see:Gutman AL, Etinger G, Nisnevich G, Polyak F. Tetrahedron Asymm. 1998;9:4369-4379;

(h) Colyer JT, Andersen NG, Tedrow JS, Soukup TS, Faul MM. J Org Chem. 2006;7:6859-6862.

5. Lu C, Zhou Q Yan J, Du Z, Huang L, Li X. Eur J Med Chem. 2013;62:745-753.

6. Glennon RA, Ismaiel M, Smith JD, et al. J Med Chem. 1991;34:1855-1859.

7. Bosch MP, Campos F, Niubo I, et al. J Med Chem. 2004;47:4041-4053.

8. (a) For reviews on organocatalyzed enantioselective reductions see: Benaglia $\mathrm{M}$, Genoni A, Bonsignore M. Enantioselective organocatalytic reductions in Stereoselective Organocatalysis: From C-C to C-heteroatom bond formation, (Ed. R. Rios Torres) Wiley, 2012.;

(b) Rossi S, Benaglia M, Massolo E, Raimondi L. Catal Sci Technol 2014, 9, 27082723. Reviews on $\mathrm{HSiCl} 3$-mediated reductions.;

(c) Reviews on $\mathrm{HSiCl}_{3}$-mediated reductions: Guizzetti S, Benaglia M. Eur J Org Chem. 2010;5529-5541;

(d) Jones S, Warner CJA. Org Biomol Chem, 2012, 10, 2189-2200.;

(e) . For representative metal-catalyzed reductions of N-1-phenylethyl imines see:Eleveld MB, Hogeveen H, Schudde EP. J Org Chem. 1986;51:3635-3638;

(f) Ranu BC, Sarkar A, Majee A. J Org Chem. 1997;62:1841-1842; 
(g) For a recent contribution on a sequential reductive aminationhydrogenolysis see: Nugent TC, Negru DE, El-Shazly M, Hu D, Sadiq A, Bibi A Adv Synth Catal, 2011, 353, 2085-2092 and references cited.

(h) . For organocatalytic reductions of chiral imines, see:Farrell JM, Heiden ZM, Stephan DW. Organometallics. 2011;30:4497-4500.

(j) Guizzetti S, Benaglia M, Biaggi C, Celentano G. Synlett. 2010;134-136.

9. Guizzetti S, Benaglia M, Rossi S. Org Lett. 2009;11:2928-2932.

10. Barrulas PC, Genoni A, Benaglia M, Burke AJ. Eur J Org Chem. 2014;7339-7442.

11. Gutman AL, Etinger M, Nisnevich G, Polyak F. Tetrahedron Asymmetry. 1998;9:4369-4379.

12. Astellas Pharma Inc., Patent: US2014/88080 A1; 2014.
13. Colyer JT, Andersen NG, Tedrow JS, Soukup TS, Faul MM. J Org Chem. 2006;71:6859-6862.

14. Review: Porta R, Benaglia M, Puglisi A. Org Process Res Dev. 2016;20:2-25.

15. (a) Brenna D, Benaglia M, Porta R, Fernandes S, Burke A. J Eur J Org Chem. 2016. http://dx.doi.org/10.1002/ejoc.201601268;

(b) For a pioneer work in the field of in-flow imine reduction see: Saaby $\mathrm{S}$, Knudsen KR, Ladlow M, Ley SV. Chem Commun, 2005, 2909-2911;

(c) . For recent reviews:Lange $\mathrm{H}$, Carter CF, Hopkin MD, et al. Chem Sci. 2011:2:765-769;

(d) Irfan M, Glasnov TN, Kappe CO. ChemSusChem. 2011;4:300-316. 